\title{
First report of multiple drug resistance in trichostrongyles affecting sheep under field conditions in Italy
}

Donato Traversa $\cdot$ Barbara Paoletti $\cdot$

Domenico Otranto $\cdot$ James Miller

Published online: 4 March 2008

(C) Springer-Verlag 2008

Erratum to: Parasitol Res (2007) 101(6):1713-1716

DOI: 10.1007/s00436-007-0707-4

The original version of this article unfortunately contained a mistake.

In particular, the correct dosage for sheep included in Group 4 and treated with Moxidectin $\left(\right.$ Cydectin $^{\circledR}$, Fort Dodge Animal Health) was $0.2 \mathrm{mg} / \mathrm{kg}$ and not $0.4 \mathrm{mg} / \mathrm{kg}$, as erroneously written in the paper.

The online version of the original article can be found at http://dx.doi. org/10.1007/s00436-007-0707-4

D. Traversa $(\bowtie) \cdot$ B. Paoletti

Department of Comparative Biomedical Sciences,

Faculty of Veterinary Medicine, University of Teramo,

Piazza Aldo Moro 45,

64100 Teramo, Italy

e-mail: dtraversa@unite.it

D. Otranto

Department of Animal Health and Welfare,

Faculty of Veterinary Medicine, University of Bari,

Valenzano (Bari), Italy

J. Miller

Department of Pathobiological Sciences,

School of Veterinary Medicine, Louisiana State University,

Baton Rouge, LA, USA 